\title{
The Impact of PMIS Training: Patterns of Benefit Realization in Project Management Information Systems Training
}

\author{
Andrew McCarty ${ }^{1}$ and Mirosław Skibniewski ${ }^{2}$ \\ ${ }^{1}$ Senior Project Manager and Specialist, School of Public Health, University of Maryland, College Park, \\ MD 20742, USA, E-mail: amccart2@umd.edu (corresponding author). \\ ${ }^{2}$ Professor, Department of Civil \& Environmental Engineering, University of Maryland, College Park, \\ MD 20742, USA, E-mail: mirek@umd.edu
}

\author{
Project Management \\ Received January 3, 2016; received revisions March 11, 2016; July 6, 2016; accepted July 8, 2016 \\ Available online July 25, 2016
}

\begin{abstract}
The benefits of project, program, and portfolio management software toolsets can be enhanced through training. Little is known about the realization of positive, beneficial outcomes and Project Management Information System (PMIS) training. This research seeks to improve understanding of project management software toolset training practices and outcomes. This study examines the prevalence, effectiveness, and impact-per-hour efficiency of training in real-world organizations. We further explore relationships between individual and organizational characteristics and training outcomes. Formulae for estimating training costs are derived using regression modeling. Surveys were collected from 1,021 active professionals and analyzed using quantitative methods. Research participants were practitioners recruited by eight different companies, industry groups, and professional organizations within the PMIS community. The findings of this research indicate significant differences in utilization, efficacy, and efficiency of PMIS training in practice. The outcomes and methodologies of this study are being incorporated into ongoing research that focuses on improving PMIS training delivery, evaluation, and planning. The outcomes of this research may result in more effective, efficient, and economical PMIS training that is better tailored to the unique needs of each organization.
\end{abstract}

Keywords: Project management information system (PMIS), project management software, workplace learning, training evaluation.

\section{Introduction}

Research is published each year on the large number of projects that fail to accomplish objectives. Organizations are spending large sums of money to deploy computerized project management (PM) software tools to improve project outcomes. Due to the growing demand for project management skills, many universities offer project management courses, both as core courses and electives (Pant and Baroudi, 2008). The management of projects has become a critical area of investment for companies across a range of industries and an essential element of MBA and executive education curricula (Berggren and Söderlund, 2008). However, organizations often lack the stakeholder buy-in, knowledge, and toolset skills necessary to maximize the value of project management software systems.

Training is used extensively in the workplace. A large volume of research has documented the ability of training to convey important knowledge, build skills, and enhance performance capabilities (Bedwell and Salas, 2010; Bulut and Culha, 2010). Studies demonstrate that knowledge can enhance deliverable quality, improve customer satisfaction, and decrease project completion times (Love et al., 2003). The impact outcomes and relative effectiveness of different delivery methods have been studied in a substantial number of previous studies (Sitzmann et al., 2006). Many techniques to rigorously evaluate the quantitative and qualitative impacts of workplace training have been developed (Kirkpatrick and Kirkpatrick, 2006; Phillips and Phillips, 2007). However, there is currently little research available on training consumption, effectiveness, and efficiency within the context of computerized toolsets to improve the management of projects, programs, and portfolios.

\section{Conceptual Development}

\subsection{Project Management Information Systems}

Starting in the middle of the last century, organizations began adopting special software and computerized tools to improve the management of projects. In the following decades, adoption continued to grow, and at present time, the utilization of specialized software systems to improve project, program, and portfolio management (PPPM) is 
extensive (Symons, 2009; Davis, 2012). These tools are used to plan and control the vital sequencing of activities and play a critical role in project management (Nguyen and Chua, 2014). PM software tools are used by a wide variety of diverse organizations and numerous industries. In spite of their prevalence and extensive use, however, there is currently no standard definition of a Project Management Information System (PMIS) or common meaning in either industry or academia. Indeed, the processes and tools used to support PPPM are unique in every organization. Researchers have employed a variety of different approaches in defining PMIS in the literature (Jaafari and Manivong, 1998; Raymond and Bergeron, 2008; Wei et al., 2008).

The objective of this study is to produce outcomes that are meaningful to the whole community of PMIS toolset users, despite differences in unique individual and organizational attributes. Properties like the particular PM software tools being used, years of experience using PM tools, industry focus, typical project size, and number of projects will naturally vary widely between different PMIS users. This research seeks to examine the tools that are actually being used by organizations. Consequently, this study focuses on all software and supporting systems used to manage projects, programs, or portfolios. In addition, PMIS is defined in this research to also include business processes, policies, and workflows which help establish how the tools are utilized. This is consistent with the approach employed by Kaiser and Ahlemann (2010), who define PMIS incorporating a conceptually broad understanding of PPPM.

\subsection{Benefits of PMIS Utilization}

Computerized project management tools facilitate enhanced planning, tracking, reporting capabilities, improved decision-making, reduced costs, streamlined operations, more consistent project outcomes, and improved performance (Project Management Institute, 2008; Kastel, 2009). Raymond and Bergeron (2008) conclude that utilizing PM software tools can enhance effectiveness, efficiency, and productivity in project managers. Improved resource scheduling, issue management, and change management capabilities help keep projects on budget (Rapport, 2009). Advanced portfolio planning and management capabilities enable organizations to better prioritize projects, eliminate lowvalue projects, and reduce project failure rates (Symons, 2009).

\subsection{Training Practices in the Modern Workplace}

Training is one of the most commonly used techniques to promote increased productivity in individuals (Galanou and Priporas, 2009). Many studies have shown training to be an effective technique to enhance knowledge, performance, skills, and competences like computer skills (Salas and Cannon-Bowers, 2001). Many delivery methods are detailed in the training literature, including traditional face-to-face training, blended approaches, electronic delivery, and others (ASTD, 2010). Advances in technology and training delivery are enabling organizations to deliver learning more conveniently and at reduced cost (Aguinis and Kraiger, 2009). A large number of variables are documented in the literature that can effect training outcomes including participant motivation, nature of pretraining conditions, management support, relevance of training to audience, positive organizational environment, performance of needs analysis assessment, and other unique individual and situational characteristics. McCarty and Skibniewski (2015) present a detailed review of workplace training in the literature. This review is discussed in greater detail in section 3.1.

\subsection{Training on Project Management Information Systems}

Annual studies of workplace training convey broadly summarized practices and trends concerning how training is being delivered within organizations. However, research that specifically addresses PMIS training delivery is extremely limited. In a study examining PM software use and training, project managers were asked about which PM software tools they used, amount and type of use, satisfaction with the tools, amount of training received on PM software, perceived adequacy of training on the tools, and overall adequacy of PM software tools (Fox and Spence, 1998). The study findings indicated that being given training on a PM toolset lead to increased user satisfaction levels with the tool. Satisfaction with the adequacy of PM software training was found to be related to greater satisfaction with the PM software application. Another study that examined PM software use and training found differing results. No significant relationship was observed between amount of training received and the use of PM software tools. (Ali et al., 2008). However, a majority of those surveyed reported only receiving minimal PM toolset training or none whatsoever. Furthermore, $80 \%$ of study participants reported having more than 4 years of experience using PM software tools.

\subsection{Hypothesis Development}

The existing research is somewhat mixed but generally shows that training effectiveness is not influenced by delivery method (Russell, 2001). However, previous studies have largely examined training delivered in precisely moderated scientific settings. Considerably fewer studies have examined real-world workplace training being delivered in modern organizations. Therefore, little information is currently available regarding how organizations are actually delivering PMIS training. We thus posit our first hypothesis:

Hypothesis 1: Significant differences exist in the utilization of various training delivery methods to deliver PMIS training in modern organizations.

While the use of PM software tools continues to grow, there is little information available on which delivery methods are producing the best PMIS training outcomes. To assess PMIS training impact, participants were prompted to evaluate the training they received via each delivery method in the previous 12 months, and assign scores for positive impacts on their individual PMIS proficiency levels and the competencies of their organizational units. In addition, respondents were asked to evaluate their skill levels one year ago before receiving training, and their current skill levels after training. Experimental design prevents the use of scientifically controlled testing and data collection methodologies to objectively measure learning outcomes in this study. However, self-reported training outcome assessment data is identified in the literature as a reliable data source for evaluating training outcomes (Phillips and Stone, 2002). The unique perspective of training participants enables 
them to accurately evaluate training outcomes. We therefore hypothesize:

Hypothesis 2: Significant differences exist between delivery methods in effectiveness at producing desirable PMIS outcomes.

Previous research suggests that certain delivery methods can permit training objectives to be accomplished while reducing the cost and time required for training (Dossett and Hulvershorn, 1983). However, information about training technique efficiency in learning costs, time invested, or increasing PMIS toolset proficiency levels is not available. To examine impact-per-hour efficiency outcomes, respondents were asked how many hours they spent participating in training via each of the examined delivery methods in the past year. The training impact data used to evaluate Hypothesis 1 was combined with the time spent in training to generate a training efficiency metric to quantify the impact of training per unit time spent participating in training. Research participants were asked to provide approximate training costs, if known. Thus, we hypothesize:

Hypothesis 3: Significant differences exist between delivery methods in impact-per-hour efficiency at producing desirable training outcomes.

Organizations that could benefit from boosting the positive outcomes of their PM toolsets through training need to understand how unique characteristics in people and organizations impact training needs and results. There is currently little available research concerning specific relationships between individual factors, organizational characteristics, PMIS training needs, and the outcomes of PMIS training activities. We therefore hypothesize:

Hypothesis 4: PMIS Training requirements and outcomes differ based on unique individual and organizational characteristics.

\section{Methodology}

\subsection{Research Instrument Development}

This research builds on previous and ongoing studies in the areas of workplace learning and PMIS training. To develop a better understanding of workplace training, a systematic review of literature was conducted in the domains of training and development (McCarty and Skibniewski, 2015). This study examined workplace training covering a broad range of topics but did not examine PMIS or project management training. The review revealed an abundance of benefits to individuals, teams, and entire organizations resulting from workplace training. A PMIS training evaluation framework has also been proposed to enhance planning, measurement, understanding, and further study of PMIS training initiatives (McCarty and Skibniewski, 2014) building on prior benefits realization theory (Aguinis and Kraiger, 2009). The framework components function as benchmarks which researchers and practitioners can use to evaluate whether a conditions present and the extent to which it occurs.

Building on the conceptual foundations of these related research efforts, this study examines real-world PMIS training practices and outcomes in professionals working in PM-oriented fields. To promote wide participation by practitioners, an electronic survey instrument was identified as the best-aligned data collection methodology. Due to the absence of research available on PM toolset training, we hypothesize that the potential beneficial outcomes of PMIS training are the benefits offered by (A) computer programs for managing projects, programs, and portfolios information, (B) workplace training activities, and (C) implementing a formal approach to PPPM. The survey instrument was developed incorporating the body of survey research literature (Groves, 2009; DeVellis, 2012) and pretested by twenty one researchers from an academic collegium dedicated to PM-focused research. The survey instrument is presented by McCarty and Skibniewski (2012).

\subsection{Data Collection}

To collect the data for this study, industry partnerships were established with eight major companies, industry groups, and professional organizations that are active in the PMIS community. Each organization invited to participate in this study was selected on the basis of visible leadership in the professional PMIS and/or training professional communities. The survey instrument was distributed via participating organizations' websites, electronic newsletters, and email communications. This research specifically targeted practitioners who regularly used computerized PMIS systems or use information produced by these tools to enhance project, program, and/or portfolio management. These professionals may have completed training activities in the past year that strengthened their abilities with these tools, or perhaps not. The practioners targeted as research participants were chosen because their day-to-day use of PMIS toolsets provides unique insight and perspective insight into current industry practices.

\section{Results and Discussion}

\subsection{Practitioner Data Sample Characteristics}

Data was collected for this research using a survey instrument from 1,021 professionals who actively work in project-oriented organizations. Completed surveys were collected from eight professional organizations, industry groups, and companies that actively provide visible leadership in the PMIS community. In alphabetical order, data was collected in partnership with the following organizations: American Society of Professional Estimators (ASPE); Clarizen, Inc.; Edwards Performance Solutions; International Institute of Business Analysis (IIBA); Microsoft Project User Group (MPUG); National Precast Concrete Association (NPCA); and Yahoo Cooperative Network for Building Researchers Group (cnbr-i).

In an effort to collect data that would allow for the best generalization of research findings to the global population of PMIS toolset users, this research targeted a wide range of respondents. Projects were found to vary widely in complexity, typical project duration, and project size. Consistent with research goals, significant diversity was observed in the years of experience respondents had with PM software, how long PM software had been used in each organization, typical number of projects managed simultaneously, and each organization's primary industry focus.

The total quantities of practitioner surveys collected for this research on behalf of each participating organization are listed in Table 2, where every organization is designated by a unique letter from $\mathrm{A}$ 
through G. Because of sizable variations between organizations in fundamental properties like size, mission, and industry focus, varying quantities of practitioner responses were expected from each organization. However, the focus of this research nevertheless remains to explore the actual global population of PM software users to the fullest extent possible. An analysis methodology has been employed that quantitatively treats the practitioner data like it was collected from a single sample of the PMIS toolset using community since the true population is amorphous, diverse, and difficult to quantify or analyze numerically. Consequently, detailed between-groups analysis evaluating nuanced differences between each participating organization is not a focus of this research. Tables 1 and 3 present sample statistics and demographic information in terms of total response frequency and percentage of overall survey responses.

Table 1. Descriptive statistics: practitioner data sample

\begin{tabular}{|c|c|c|c|c|c|c|c|c|c|c|c|}
\hline \multicolumn{6}{|c|}{ Characteristics of Research Participants } & \multicolumn{6}{|c|}{ Did You Receive PMIS Training in Past Year? } \\
\hline & Mean & Std. Dev & Min & Max & $\mathrm{N}$ & \multirow{4}{*}{$\begin{array}{l}\text { If your org. unit uses PM } \\
\text { software, did you receive } \\
\text { beneficial training in the } \\
\text { past year via any of the } \\
\text { six examined delivery } \\
\text { methods? }\end{array}$} & \multicolumn{2}{|c|}{ Yes } & \multicolumn{2}{|c|}{ No } & \multirow[t]{2}{*}{$\mathrm{N}$} \\
\hline $\begin{array}{l}\text { Yrs. of PM-Related } \\
\text { Prof. Exper }\end{array}$ & 12.2 & 9.3 & 0 & $40+$ & 1,021 & & Freq. & $\%$ & Freq. & $\%$ & \\
\hline $\begin{array}{l}\text { Yrs. of PM Software } \\
\text { Experience }\end{array}$ & 7.9 & 7 & 0 & $40+$ & 1,021 & & \multirow[t]{2}{*}{596} & \multirow[t]{2}{*}{65.4} & \multirow[t]{2}{*}{315} & \multirow[t]{2}{*}{34.5} & \multirow[t]{2}{*}{911} \\
\hline $\begin{array}{l}\text { Hrs. of PMIS Training } \\
\text { in Past Year }\end{array}$ & 14.7 & 17.1 & 0 & $40+$ & 596 & & & & & & \\
\hline \multicolumn{6}{|c|}{ Does Your Organizational Unit Use PM Software? } & \multicolumn{6}{|c|}{ Delivery of Training in Past Year } \\
\hline \multirow{8}{*}{$\begin{array}{l}\text { Are specialized } \\
\text { software tools used to } \\
\text { enhance project, } \\
\text { program, and/or } \\
\text { portfolio } \\
\text { management? }\end{array}$} & \multicolumn{2}{|c|}{ Yes } & \multicolumn{2}{|c|}{ No } & $\mathrm{N}$ & \multirow{2}{*}{$\begin{array}{l}\text { If you received PMIS } \\
\text { training in the past year, } \\
\text { how was the training } \\
\text { delivered? }\end{array}$} & \multicolumn{2}{|c|}{ Yes } & \multicolumn{2}{|c|}{ No } & $\mathrm{N}$ \\
\hline & Freq. & $\%$ & Freq. & $\%$ & & & Freq. & $\%$ & Freq. & $\%$ & \\
\hline & \multirow{6}{*}{911} & \multirow{6}{*}{89.2} & \multirow{6}{*}{110} & \multirow{6}{*}{10.8} & \multirow{6}{*}{1,021} & Web-Based & 344 & 37.7 & 567 & 62.2 & 911 \\
\hline & & & & & & Classroom & 279 & 30.6 & 632 & 69.4 & 911 \\
\hline & & & & & & Coaching or Mentoring & 220 & 24.1 & 691 & 75.9 & 911 \\
\hline & & & & & & Lunch \& Learn & 208 & 22.8 & 703 & 77.2 & 911 \\
\hline & & & & & & Prof. Orgs. & 165 & 18.1 & 746 & 81.9 & 911 \\
\hline & & & & & & Conference & 132 & 14.4 & 779 & 85.5 & 911 \\
\hline
\end{tabular}

\subsection{PMIS Training Consumption by Delivery Method}

The survey results show that $89.23 \%$ of research participants $(911$ of 1,021$)$ reported that PM software is used by their organizations while $10.77 \%$ (110 of 1,021$)$ responded that PM software is not used within their organizations to manage projects. Among the research participants who indicated that PM software is used by their organizations, only $65.42 \%$ (596 of 911) stated that they had received beneficial PM software toolset training in the previous year via any of the examined training delivery methods, while $34.58 \%$ (315 of 911) did not receive any training. Overall, the average number of hours of relevant training received through the 6 delivery methods examined in this research was 24.50 hours with a standard deviation of 30.69. A total of 1,348 unique data points were reported by the 596 recipients of beneficial training.

Web-based training was reported by the largest number of research participants. In total, $33.69 \%$ of respondents reported receiving web-based training related to project management toolset usage in the past 12 months (344 of 911). Classroom training was reported by $27.33 \%$ of research participants (279 of 911). Coaching or mentoring was reported by $21.55 \%$ of participants $(220$ of 911). "Lunch and Learn" style training sessions were reported by $20.37 \%$ of participants (208 of 911), participation in professional organizations was reported by $16.16 \%$ (165 of 911), and conference attendance was reported by $12.93 \%$ (132 of 911).

Practitioners who received classroom training received an average of 19.64 hours of classroom training in the past
12 months. Those who received training through coaching or mentoring received an average of 15.91 hours of PMISrelated coaching/mentoring in the past 12 months. Respondents who reported conference attendance received a mean of 15.35 hours of PMIS training through conference attendance in the previous year. Practitioners who received training via participation in professional organizations received an average of 14.28 hours training through professional organizations training in the past 12 months. Consumers of web-based training received a mean of 13.92 hours of web-based training in the past year. Finally, participants in "Lunch and Learn" training sessions consumed a mean of 7.84 hours of PMIS-related training through "Lunch and Learn" sessions in the past 12 months.

To better understand how modern organizations are using different delivery methods to provide PMIS knowledge, hours of PMIS training received was examined based on training delivery method using a oneway mixed effects ANOVA quantitative assessment. In this examination, training delivery method is considered a random independent variable, and number of training hours received is treated as a fixed dependent variable. Statistically significant differences were observed in the use of the examined training delivery methods to provide PMIS training $\left(\mathrm{F}_{5,1342}=2.22 ; \mathrm{p}=0.001\right)$. Means and standard deviation statistics for the number of training hours reported by practitioners, training impact, and impact-per-hour efficiency of training are shown in Tables 4-6. 
Table 2. Research participants recruited by each organization

\begin{tabular}{cc}
\hline Organization & Completed Surveys Submitted \\
\hline A & 789 \\
B & 91 \\
C & 46 \\
D & 44 \\
E & 35 \\
F & 8 \\
G & 8 \\
Total & 1,021 \\
\hline
\end{tabular}

Table 3. Data sample composition and research variable constructs

\begin{tabular}{|c|c|c|c|c|c|c|c|c|}
\hline \multicolumn{3}{|c|}{$\begin{array}{l}\text { Number of Projects Managed } \\
\text { Simultaneously }\end{array}$} & \multicolumn{3}{|c|}{ Duration Org. Has Used PM Software } & \multicolumn{3}{|c|}{ Typical Size of Projects } \\
\hline & Freq. & $\%$ & & Freq. & $\%$ & & Freq. & $\%$ \\
\hline 1 Project & 33 & 3.2 & $<6$ months & 47 & 4.6 & $\begin{array}{c}1-5 \mathrm{FT} \\
\text { Professionals }\end{array}$ & 368 & 36 \\
\hline 2-3 Projects & 158 & 15.5 & $6 \mathrm{mo}$. to $1 \mathrm{yr}$. & 36 & 3.5 & $\begin{array}{c}\text { 6-20 FT } \\
\text { Professionals }\end{array}$ & 449 & 44 \\
\hline 4-5 Projects & 186 & 18.2 & 1 yr. to 2 yrs. & 82 & 8.0 & $\begin{array}{c}21-50 \mathrm{FT} \\
\text { Professionals }\end{array}$ & 113 & 11.1 \\
\hline 6-10 Projects & 178 & 17.4 & $3-5$ yrs. & 204 & 20.0 & $\begin{array}{l}51-100 \text { FT } \\
\text { Professionals }\end{array}$ & 36 & 3.5 \\
\hline $10+$ Projects & 447 & 43.8 & $6+\mathrm{yrs}$ & 475 & 46.5 & $\begin{array}{c}100+\mathrm{FT} \\
\text { Professionals }\end{array}$ & 37 & 3.6 \\
\hline Not Known & 19 & 1.9 & Not Known & 177 & 17.3 & Not Known & 18 & 1.8 \\
\hline Total & 1,021 & 100.0 & Total & 1,021 & 100.0 & Total & 1,021 & 100.0 \\
\hline \multicolumn{3}{|c|}{ Primary Role of Respondent } & \multicolumn{3}{|c|}{ Industry Focus } & \multicolumn{3}{|c|}{ Typical Complexity of Projects } \\
\hline & Freq. & $\%$ & & Freq. & $\%$ & & Freq. & $\%$ \\
\hline Project Contributor & 78 & 7.6 & Aerospace & 12 & 1.2 & 1 - Not Complex & 12 & 1.2 \\
\hline Researcher & 14 & 1.4 & Automotive & 15 & 1.5 & 2 & 21 & 2.1 \\
\hline Educator/Trainer & 11 & 1.1 & Construction & 95 & 9.3 & 3 & 47 & 4.6 \\
\hline PM Consultant & 48 & 4.7 & Consulting & 99 & 9.7 & 4 & 116 & 11.4 \\
\hline Functional Manager & 55 & 5.4 & Energy & 38 & 3.7 & 5 & 306 & 30.0 \\
\hline PM Specialist & 13 & 1.3 & $\begin{array}{l}\text { Finance-Related } \\
\text { Services }\end{array}$ & 194 & 19 & 6 & 323 & 31.6 \\
\hline Scheduling Professional & 6 & 0.6 & Food/Beverage & 15 & 1.5 & 7 - Very Complex & 186 & 18.2 \\
\hline Project Manager & 156 & 15.3 & Government/Public & 97 & 9.5 & Not Known & 10 & 1.0 \\
\hline Program Manager & 53 & 5.2 & Healthcare/Medicine & 64 & 6.3 & Total & 1,021 & 100.0 \\
\hline Portfolio Manager & 11 & 1.1 & Info. Technology & 170 & 16.7 & \multicolumn{3}{|c|}{ Typical Project Duration } \\
\hline Director of PM/PMO & 28 & 2.7 & Legal/Law & 2 & 0.2 & & Freq. & $\%$ \\
\hline Executive Leadership & 71 & 7 & Manufacturing & 27 & 2.6 & $<6$ months & 140 & 13.7 \\
\hline Other & 477 & 46.7 & Mining & 0 & 0 & $6 \mathrm{mo}$. to $1 \mathrm{yr}$. & 450 & 44.1 \\
\hline \multirow[t]{5}{*}{ Total } & 1,021 & 100.0 & Pharmaceutical & 18 & 1.8 & 1 yr. to 2 yrs. & 317 & 31.0 \\
\hline & & & Telecom & 36 & 3.5 & $3-5$ yrs. & 80 & 7.8 \\
\hline & & & Training/Education & 29 & 2.8 & $6+\mathrm{yrs}$ & 18 & 1.8 \\
\hline & & & Other & 110 & 10.8 & Not Known & 16 & 1.6 \\
\hline & & & Total & 1,021 & 100.0 & Total & 1,021 & 100.0 \\
\hline
\end{tabular}




\subsection{Effectiveness of Training Delivery Methods}

Previous research has generally shown that training delivery methods tend to be equally effective at producing outcomes when training is delivered under carefully controlled conditions. However, this research focuses on real-world training delivered in practice and whether there are differences in the training outcomes created by different delivery methods. Specifically, this research examines the effect of delivery method on PMIS training outcomes, PMIS proficiency levels in individuals, and PMIS competencies in organizations. Analysis was performed using a multi-way mixed effects ANOVA methodology. In this analysis, delivery method was evaluated as a random independent variable. The selfevaluated individual PMIS proficiency levels and organizational competencies reported by practitioners were treated as a fixed dependent variable, expressed as the aggregated total score of each research participant on the entire span of individual/organizational areas. In this analysis, the independent variable is nominal, whereas the dependent variable occurs at a ratio scale and has a highest value possible of 42 .

The findings of this analysis indicate that practitioners did indeed experience a statistically-significant difference in perceived training impact $\left(\mathrm{F}_{5,1342}=2.22 ; \mathrm{p}<0.001\right)$ due to the training delivery method used to administer PMIS training. With a highest possible score of 42, classroom training produced the greatest reported impact at 26.36 . The second highest impact reported was generated by coaching/mentoring at 25.42 , followed third by conference attendance at 24.41, web-based training fourth at 23.33, professional organizations fifth at 22.98, and "Lunch and Learn" training last at 21.42 producing the smallest impact of the examined delivery methods. The average training impact score across all delivery methods was 24.06. The observed F statistic value was 7.149, greater than the critical value of 2.221. Consequently, the variation between groups is much greater than the variation within groups and the null hypothesis is rejected. The resulting Sig. value of 0.000 is less than $\alpha$. Therefore, it appears that the findings of this analysis are significant and unlikely to result from coincidence or random chance. Thus, these results indicate that the delivery method used to administer PMIS training does result in a statistically significant difference in PMIS training effectiveness and impact.

\subsection{Efficiency of Training Delivery Methods}

To establish a metric to quantify and evaluate PMIS training efficiency, the dependent variable is defined as the aggregated training impact score reported by research participants, totaled through each individual and organizational discipline. This sum was then divided by the number of hours respondents spent attending the training session resulting in an impact-per-hour measure of PMIS training efficiency. A multi-way mixed effects ANOVA analysis model was utilized to examine PMIS training efficiency. PMIS training delivery method was analyzed as a nominal-level random independent variable, while the dependent variable is treated as occurring at a ratio level of measurement. Training delivered via "Lunch and Learn" sessions resulted in the greatest impact-perhour of all of the examined delivery methods with the largest overall mean efficiency score of 6.53. In descending order, the second-most efficient delivery method was coaching/mentoring with a score of 5.44, followed third by web-based training at 5.22, conference participation fourth at 4.61 , classroom training fifth at 4.21 , and professional organizations as the least efficient examined delivery method with a mean efficiency score of 3.86. The findings of this research question indicate a mathematically significant difference in the impact-pertime efficiency of these popular training delivery methods as they are actually being used by organizations in industry. The observed value $\mathrm{F}=4.885$ is greater than the 2.221 critical value $\left(\mathrm{F}_{5,1342}=2.221 ; \mathrm{p}<0.001\right)$. The sig. value observed was equal to 0.001 , which is less than $\alpha=.05$. Consequently the null hypothesis is rejected and these findings are again significant and not likely to be the result of chance alone.

Table 4. Hours of training reported means analysis

\begin{tabular}{cccc}
\hline Training Delivery Method & Mean & Std. Dev. & $\mathrm{N}$ \\
\hline Classroom & 19.64 & 18.91 & 279 \\
Coaching or Mentoring & 15.91 & 18.56 & 220 \\
Conference Participation & 15.35 & 14.88 & 132 \\
Prof. Orgs. & 14.28 & 17.50 & 165 \\
Web-Based & 13.92 & 17.36 & 344 \\
Lunch \& Learn & 7.84 & 10.09 & 208 \\
Total & 14.67 & 17.14 & 1348 \\
\hline
\end{tabular}

Table 5. Impact of PMIS training means analysis

\begin{tabular}{cccc}
\hline Training Delivery Method & Mean & Std. Dev. & N \\
\hline Classroom & 26.36 & 10.28 & 279 \\
Coaching or Mentoring & 25.42 & 10.38 & 220 \\
Conference Participation & 24.41 & 9.95 & 132 \\
Web-Based & 23.33 & 10.16 & 344 \\
Prof. Orgs. & 22.98 & 10.55 & 165 \\
Lunch \& Learn Training & 21.42 & 9.79 & 208 \\
Total & 24.06 & 10.31 & 1348 \\
\hline
\end{tabular}




\subsection{PMIS Training and Connections with Other Variables}

Numerous individual and organizational characteristics are documented in the literature that may impact PMIS training requirements and outcomes. This study examines years of professional experience in the field of project management, years of experience using PM software tools, primary role of professionals, industry focus, amount of time organizations have used PM software, typical project sizes, durations, complexity, projects managed simultaneously, PMIS training hours received in the past year, and specific training delivery methods being used.

To find possible connections between individual respondent characteristics, organizational properties, and PMIS training practices, a corrected analysis of multiple one way ANOVA comparison procedures was used to examine every variable. The elevated overall Type I error rate that occurs naturally as the result of multiple significance tests was controlled using a Bonferroni correction. which was used because it inherently tends to be overly conservative when multiple significance tests are employed (Cheverud, 2001). The Bonferroni correction procedure results computationally in reduced significance thresholds. Because this analysis employs seven comparison procedures, the adjusted significance thresholds are equal to $\alpha / \mathrm{N}=0.05 / 7=0.007143$.

When the primary role of research participants was analyzed as an independent variable, it was observed to impact typical project size $(\mathrm{F}=3.427 ; \mathrm{p}=0.000059)$ and complexity $(\mathrm{F}=3.922 ; \mathrm{p}=0.000006)$ with critical values of $\mathrm{F}$ equal to $\mathrm{F}_{(12,1,008)}=1.762$ in both cases. Analysis of typical project complexity as an independent variable demonstrated a statistical relationship with project size $(\mathrm{F}=11.841 ; \mathrm{p}=0.000000)$, typical project duration $(F=11.318 ; p=0.000000)$, and use of PM software tools to manage projects by the organization $(\mathrm{F}=4.683$; $\mathrm{p}=0.000104)$. The observed critical value of $\mathrm{F}_{(6,1,014)}=$ 2.108 for all three of these cases. Typical number of projects and the organization's industry focus did not generate evidence of meaningful relationships when analyzed as independent variables. Analyzing typical project duration as an independent variable produced findings that suggest relationships with typical project size $(\mathrm{F}=40.645 ; \mathrm{p}=0.000000)$, typical project complexity $(\mathrm{F}=8.742 ; \mathrm{p}=0.000000)$, and the amount of time that PM software has been used by the organization to manage projects $(\mathrm{F}=4.387 ; \mathrm{p}=0.000588)$ with critical values of $\mathrm{F}_{(5}$, $1,015)=2.223$ in all three cases.

Isolating and analyzing typical project size as an independent variable produced mathematically significant relationships with project complexity $(\mathrm{F}=12.187$; $\mathrm{p}=0.000000$ ), use of PM software tools to manage projects
$(\mathrm{F}=3.709 ; \mathrm{p}=0.002482)$, and typical project duration $(\mathrm{F}=58.118 ; \mathrm{p}=0.000000)$. When the independent variable was whether or not the organization uses specialized PM software tools to manage projects, the practitioner data showed potential relationships with typical project size $(\mathrm{F}=11.474 ; \mathrm{p}=0.000733$ and project complexity $(\mathrm{F}=19.947$; $\mathrm{p}=0.000000)$. The critical value of the $\mathrm{F}$ statistic is $\mathrm{F}_{(5,1,015)}$ $=2.223$. Finally, when the amount of time that PM tools have been used by the organization to manage projects was evaluated as an independent variable, the findings indicated relationships with industry $(\mathrm{F}=4.616$; $\mathrm{p}=0.000360)$, project complexity $(\mathrm{F}=5.790 ; \mathrm{p}=0.000028)$, typical project size $(\mathrm{F}=4.864 ; \mathrm{p}=0.000211)$, primary role $(\mathrm{F}=4.864 ; \mathrm{p}=0.000211)$, and as expected, the use of PM software tools to manage projects $(\mathrm{F}=82.324 ; \mathrm{p}=0.000000)$. The critical value of the $\mathrm{F}$ statistic for this portion of the analysis is $\mathrm{F}_{(5,1,015)}=2.223$.

To examine potential relationships between variables and assess the strength and directionality of relationships, a Pearson product-moment correlation analysis was performed. Training impact, hours of training, training efficiency, years of PM-related professional experience, and years of experience using PM software were included as variables in this analysis subsection. The outcomes of the Pearson product-moment bivariate correlation analysis $(\mathrm{N}=1,348)$ are presented in Table 7 . Variables that were observed to be both correlated and significantly related are identified with asterisks $(*)$ in Table 7 . Hours of training consumed and training impact were observed to be significantly related and positively correlated $(\mathrm{r}=0.266$; $\mathrm{p}<0.001)$. These findings imply that practitioners who receive more hours of training tend to experience better training outcomes and increased realization of training benefits by individuals and at the organizational level.

The data indicates a strong positive correlation between the number of years of PM-related professional experience and number of years using PM software $(\mathrm{r}=0.772 ; \mathrm{p}<0.001)$. This is consistent with the widespread adoption of PM software toolsets and the notion that practitioners with more years of PM experience also tend to have more experience with PM toolsets. Similarly, respondents who report more years of experience using PM toolsets likely have professional backgrounds that include more PM related experience. Years of PM-related experience $(\mathrm{r}=-0.085 ; \mathrm{p}=0.002)$ and years of project management toolset usage $(\mathrm{r}=-.099 ; \mathrm{p}<0.001)$ were both observed to be weakly negatively correlated with training impact. This implies that as levels of PM and PMIS experience increase, respondents report less training impact. A negative correlation was also observed between years of PMIS experience and training efficiency $(r=-.064$; $\mathrm{p}=0.018$ ). No other meaningful correlations were observed between the examined variables.

Table 6. Impact-per-hour of training means analysis

\begin{tabular}{cccc}
\hline Training Delivery Method & Mean & Std. Dev. & $\mathrm{N}$ \\
\hline Lunch \& Learn & 6.53 & 7.21 & 208 \\
Coaching or Mentoring & 5.44 & 7.93 & 220 \\
Web-Based & 5.22 & 6.83 & 344 \\
Conference Participation & 4.61 & 6.88 & 132 \\
Classroom & 4.21 & 6.59 & 279 \\
Prof. Orgs. & 3.86 & 4.23 & 165 \\
Total & 5.02 & 6.82 & 1348 \\
\hline
\end{tabular}


Table 7. Pearson product-moment bivariate correlation analysis

\begin{tabular}{|c|c|c|c|c|c|c|}
\hline & $\frac{\text { Pearson Correlation }}{\text { Sig. (Two Tailed) }}$ & Impact & Hours & Efficiency & $\begin{array}{l}\text { Years PM } \\
\text { Experience }\end{array}$ & $\begin{array}{c}\text { Yrs. PM } \\
\text { Software } \\
\text { Experience }\end{array}$ \\
\hline \multirow{2}{*}{ Impact } & Pears. Corr. & 1 & $.266^{*}$ & $.121^{*}$ & $-.085^{*}$ & $-.099 *$ \\
\hline & Sig. Value & & .000 & .000 & .002 & .000 \\
\hline \multirow{2}{*}{ Hours } & Pears. Corr. & $.266^{*}$ & 1 & $-.443 *$ & .014 & $.079 *$ \\
\hline & $\overline{\text { Sig. Value }}$ & .000 & & .000 & .614 & .004 \\
\hline \multirow{2}{*}{ Efficiency } & Pears. Corr. & .016 & $-.443 *$ & 1 & -.025 & $-0.64^{*}$ \\
\hline & $\overline{\text { Sig. Value }}$ & .558 & .000 & & .362 & .018 \\
\hline \multirow{2}{*}{$\begin{array}{l}\text { Years PM } \\
\text { Experience }\end{array}$} & Pears. Corr. & $-.085^{*}$ & .014 & -.025 & 1 & $.772 *$ \\
\hline & $\overline{\text { Sig. Value }}$ & .002 & .614 & .362 & & .000 \\
\hline \multirow{2}{*}{$\begin{array}{l}\text { Yrs. PM Software } \\
\text { Experience }\end{array}$} & Pears. Corr. & $-.099 *$ & $.079 *$ & $-0.64 *$ & $.772 *$ & 1 \\
\hline & $\overline{\text { Sig. Value }}$ & .000 & .004 & .018 & .000 & \\
\hline
\end{tabular}

\subsection{How Much to Pay for PMIS Training?}

At present time, organizations do not have objective means to evaluate the appropriate cost for PMIS training. An estimating methodology developed by Forrester Research titled Total Economic Impact (TEI) can be used to create insight and answers in this area. The conceptual basis underlying the methodology is a financial model that is based on reasonable projections of resource requirements, project timelines, efficiency rates, investments required in new technology, and other considerations (Symons, 2009). This research builds on the TEI methodology and uses regression modeling to generate formulae that estimate the hours of training necessary to increase PMIS proficiency levels in individuals and organizational competencies. Each of the examined training delivery methods was analyzed separately: web-based training, classroom training, "Lunch and Learn" style training, conference participation, professional organizations, and coaching/mentoring.

To capture estimated practitioner training costs, research participants were asked to quantify their approximate PMIS training costs if known or to leave blank otherwise:

"If you were to estimate, how much was spent in the past year on training sessions you received that improved your use of project, program, or portfolio management software via each of the following delivery methods? Exclude the cost of your wages, but be sure to include travel and meals."

A general equation for estimating cost based on training hours (Eq. 1) is generated using the regression analysis slope coefficients and intercept information:

$\operatorname{Cost}_{(i)}=\left(m_{\text {regress.coef. }} * t_{\text {training hrs. }}\right)+b_{\text {intercept }}$

The terms of Eq. 1 are defined such that $\operatorname{Cost}_{(i)}$ is the estimated cost of training for each delivery method and $t_{\text {traininghrs. }}$ equals the number of training hours consumed. The variable $m_{\text {regress.coef. }}$ is the hourly training cost regression coefficient, while $b_{\text {intercept }}$ equals the dollarized cost intercept at $\mathrm{t}=0$.

Formulae to estimate the cost of PMIS training delivered via each specific training delivery method can be derived from this general-form equation:

$$
\begin{aligned}
& \operatorname{Cost}_{(\text {Prof.orgs. })}=\left(t_{\text {training hrs }} * 15.83\right)+440.80 \\
& \operatorname{Cost}_{(\text {Classroom })}=\left(t_{\text {training hrs }} * 24.80\right)+877.40 \\
& \operatorname{Cost}_{(\text {Web })}=\left(t_{\text {training hrs }} * 19.36\right)+685.48 \\
& \operatorname{Cost}_{(\text {Lunch })}=\left(t_{\text {training hrs }} * 34.31\right)+277.58 \\
& \operatorname{Cost}_{(\text {Coaching })}=\left(t_{\text {training hrs }} * 17.88\right)+735.76 \\
& \operatorname{Cost}_{(\text {Conference })}=\left(t_{\text {train. }}\right. \text { hrs. }
\end{aligned}
$$

These formulae can be used to estimate costs for PMIS training based on number of training hours and delivery method. These equations are plotted in Fig. 1. This technique calculates projected PMIS training costs using real-world data, facilitating realistic and objectivelygenerated training cost estimates.

The training cost projected by the regression model for an individual who will receive 20 hours of classroom PMIS training is:

$$
\begin{aligned}
\operatorname{Cost}_{(\text {Classroom } \bullet 20 h r s)} & =(20 h * \$ 24.80)+\$ 877.40 \\
& =1,373.40 \text { Dollars }
\end{aligned}
$$

And the training cost predicted by the regression model for an individual who will receive 40 hours of PMIS-focused coaching is:

$$
\begin{aligned}
\text { Cost }_{(\text {Coaching } \bullet 40 h r s)} & =(40 h * \$ 17.88)+\$ 735.76 \\
& =1,450.96 \text { Dollars }
\end{aligned}
$$




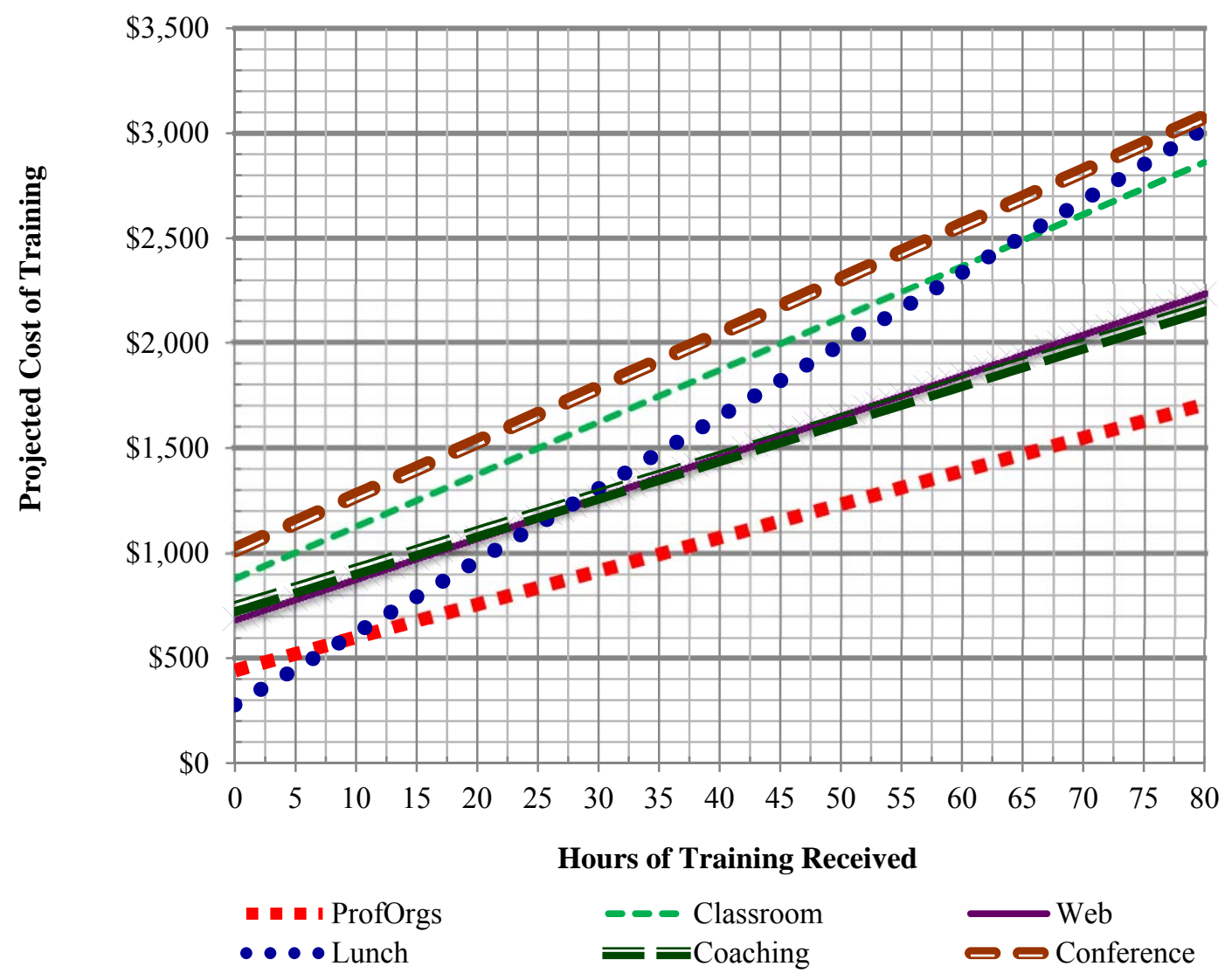

Fig. 1. PMIS training cost projection formulae

\section{Discussion and Conclusion}

In this study, we have examined PMIS training within project-focused organizations. The objective of this research is to generate greater understanding of training, practices, utilization, and outcomes. To further explore the training delivery methods modern organizations are using to deliver PMIS training, detailed training consumption statistics were generated from the practitioner survey data. Our analysis identified significant differences in the number of training hours respondents reported receiving via each examined delivery method in the past year. While studies have found different delivery methods to be largely equivalent in effectiveness when studied in controlled environments, our analysis of practitioner data indicates significant differences in effectiveness of the PMIS training that is actually delivered in practice. Though previous studies of efficiency in workplace training are limited, statistically different efficiency outcomes were observed in the practitioner training examined in this research. Training delivery methods with higher efficiency metrics demonstrated a greater impact on individual skill levels and organizational competencies per hour of training received.

To explore individual, organizational, and training characteristics that may influence PMIS training needs and outcomes, these attributes were examined using a Bonferroni-corrected multiple comparison ANOVA analysis. Our analysis identified several potential relationships between variables. These findings suggest relationships between primary role, typical project complexity, typical project size, typical project duration, whether the organization uses PM software to manage projects, and the amount of time PM software has been used by the organization to manage projects. This may be an indication that respondents in certain roles tend to work on larger, more complex projects with longer durations. These findings would also be explained by the idea that higher-complexity projects generally tend to be bigger in size, have lengthier durations, and are more likely to be executed by organizations that utilize PM software.

Pearson product-moment bivariate correlation analysis, conducted to further identify potential relationships between variables indicated that number of training hours and training impact were both positively correlated and significantly related. This is consistent with Thomas and Mullaly (2008), who suggest that more hours of training help build stronger individual proficiencies while also creating increased organizational value. In addition, the Pearson product-moment bivariate correlation findings suggested a strong positive correlation between years of professional PM-related experience and years of PM software use. This is consistent with widespread use of PM software tools to manage projects, such that practitioners with more years of PM-related experience also tend to have more experience using PM toolsets. Regression modeling was used to estimate the cost of PMIS training as a function of personnel training hours and delivery method based on cost data collected from practitioners. Our results suggest significant differences in the cost structure for each training delivery method and can be used as a basis for planning training initiatives or future research. 


\subsection{Research Implications}

The findings of this study facilitate better understanding of current PM software usage and training practices. Our study empirically extends understanding of PMIS training utilization and outcomes by providing detailed quantitative insight into industry training practices. The results of this study provide new insight into PM software utilization, delivery of training, and realization of benefits in a diverse array of organizations and industries. Our findings reinforce the idea that developments in training theory facilitate improved training evaluation, planning, and understanding of successful practices. The findings of this study have implications in enhancing training practices, improving benefits realized by stakeholders, and encouraging better training outcomes.

The outcomes of this study also have implications in promoting successful practices and outcomes in PMIS deployment efforts. This research is of additional importance because historically, organizations have been restricted in their ability to accurately assess potential training options for their organization or reasonable costs for PMIS training. Researchers, practitioners, PMO staff, consultants, executive management, training personnel, and organizations are all positioned to gain from the outcomes of this study. In addition, project owners, endusers of deliverables, and myriad additional stakeholders who have an interest in PMIS success may also benefit. Furthermore, better PMIS training may empower learners to better perform job responsibilities or teach the skills necessary for a higher-level position, thereby promoting professional growth and career development in individuals. The methodologies and outcomes of this study can be adopted to plan PMIS training, perform requirements gathering, or generate training budgets.

\subsection{Limitations and Future Research}

Because the investigational methodologies employed in this study did not allow for participants to be randomly assigned to different training groups, by definition, the research methods used technically diverge from true scientific experimental design. Since training delivery methods were statistically analyzed as unique individual data points, research participants who reported multiple training types were mathematically associated with more than one data point in some calculations. These associations implicate dependence between the examined variables. However, assumptions of independence were assessed in each analysis throughout this study and determined to be acceptable. The large sample size serves to eliminate variations in responses and increases the external validity of this research, or the degree to which findings can be accurately generalized to the greater population.

The data generated by the Likert-style scales used to examine training impact is at the ordinal level of measurement. Mathematical procedures that are meaningful when data at higher ratio or interval levels of measurement is analyzed may not have meaning at the lower ordinal level. However, the analysis conducted in this research of data at the interval level is validated through the Rasch model. (Wright, 1977). Additional research is necessary on the use of training to enhance the benefits provided by project management software tools. Merely using PMIS tools does not assure successful project outcomes since a computerized system that uses faulty processes or data inputs will produce low-quality, unreliable information (Bednarz and Dubie, 2006). It has been found that organizations that stop investing in project management begin to lose maturity almost immediately (Thomas and Mullaly, 2007). On-going research may lead to enhanced PMIS training theory and practice, greater knowledge of circumstances that positively impact PM toolset outcomes, and improved management of projects.

\section{Acknowledgements}

The authors would like to sincerely thank the following individuals and organizations for their invaluable partnership and contributions to this research. In alphabetical order: American Society of Professional Estimators (ASPE); Clarizen, Inc.; Edwards Performance Solutions; International Institute of Business Analysis (IIBA); Microsoft Project User Group (MPUG); National Precast Concrete Association (NPCA); and Yahoo Cooperative Network for Building Researchers Group (cnbr-i).

The authors would like to express their special thanks and gratitude to Debbie Cohen-Abravanel with Clarizen; Gerald Leonard with Edwards Performance Solutions; and Tracy Cook, Dave Bieg, and Kathleen Barret with the International Institute of Business Analysis (IIBA). Thanks also to Dr. Yujie (Lawrence) $\mathrm{Yu}$ for his contributions to this study.

\section{References}

Aguinis, H. and Kraiger, K. (2009). Benefits of training and development for individuals and teams, organizations, and society. Annual Review of Psychology, 60(1), 451-474. doi: 10.1146/annurev.psych.60.110707.163505

Ali, A. S. B., Anbari, F. T., and Money, W. H. (2008). Impact of organizational and project factors on acceptance and usage of project management software and perceived project success. Project Management Journal, 39(2), 5-33. doi: 10.1002/pmj.20041

ASTD (2010). 2010 state of the industry report: ASTD's annual review of trends in workplace learning and performance. Alexandria, Virginia: American Society for Training \& Development, 36.

Bednarz, A. and Dubie, D. (2006). Project mgmt. software can limit IT woes. Network World, 23(45), 131.

Bedwell, W. L. and Salas, E. (2010). Computer-based training: capitalizing on lessons learned. International Journal of Training \& Development, 14(3), 239-249. doi: $10.1111 / \mathrm{j} .1468-2419.2010 .00355 . \mathrm{x}$

Berggren, C. and Söderlund, J. (2008). Rethinking project management education: social twists and knowledge co-production. International Journal of Project Management, 26(3), 286-296. doi: 10.1016/j.ijproman.2008.01.004

Bulut, C. and Culha, O. (2010). The effects of organizational training on organizational commitment. International Journal of Training \& Development, 14(4), 309-322. doi: $10.1111 / \mathrm{j} .1468$ 2419.2010.00360.x

Cheverud, J. M. (2001). A simple correction for multiple comparisons in interval mapping genome scans. Heredity, $87(1), \quad 52-58$. doi: $10.1046 / j .1365-$ 2540.2001.00901.x

Davis, D. L. (2012). Business analytics for PPPM benefits realization. 2012 PMI Global Congress 
Proceedings, Vancouver, Canada, Project Management Institute (PMI).

DeVellis, R. F. (2012). Scale development : theory and applications. Thousand Oaks, California: SAGE, 205.

Dossett, D. L. and Hulvershorn, P. (1983). Increasing technical training efficiency: peer training via computer-assisted instruction. Journal of Applied Psychology, 68(4), 552-558. doi: 10.1037/00219010.68.4.552

Fox, T. L. and Spence, J. W. (1998). Tools of the trade: a survey of project management tools. Project Management Journal, 29(3), 20-27.

Galanou, E. and Priporas, C. V. (2009). A model for evaluating the effectiveness of middle managers' training courses: evidence from a major banking organization in Greece. International Journal of Training \& Development, 13(4), 221-246. doi: 10.1111/j.1468-2419.2009.00329.x

Groves, R. M. (2009). Survey methodology. Hoboken, New Jersey: Wiley, 461.

Jaafari, A. and Manivong, K. (1998). Towards a smart project management information system. International Journal of Project Management, 16(4), 249-265. doi: 10.1016/s0263-7863(97)00037-9

Kaiser, M. G. and Ahlemann, F. (2010). Measuring project management information systems success: towards a conceptual model and survey instrument. ECIS 2010 Proceedings, Pretoria, South Africa, 1-14.

Kastel, B. (2009). World-class enterprise projects: the essential guide to project management solutions that work - process design with SAP, PMBOK, Primavera, MS Project. Sarasota, Florida: Competetive Edge International, Inc., 308.

Kirkpatrick, D. L. and Kirkpatrick, J. D. (2006). Evaluating training programs: the four levels. San Francisco, California: Berrett-Koehler.

Love, P., Edum-Fotwe, F., and Irani, Z. (2003). Management of knowledge in project environments. International Journal of Project Management, 21(3), 155-156. doi: 10.1016/s0263-7863(02)00089-3

McCarty, A. J. (2012). Measuring the impact of training in the implementation of project management information systems, Doctoral dissertation, University of Maryland, College Park.

McCarty, A. J. and Skibniewski, M. J. (2014). Toward a framework for project management information system training. First Annual PMI/UMD Project Management Symposium, College Park, Maryland, 14

McCarty, A. J. and Skibniewski, M. J. (2015). Understanding the value of training in the professional workplace: a literature review. International Journal of Continuing Engineering Education and Life-Long Learning, 25(3), 347-358. doi: 10.1504/IJCEELL.2015.072676

Nguyen, Q. and Chua, D. (2014). Criticality of schedule constraints - classification and identification for project management. Journal of Engineering, Project, and Production Management, 4(1), 17-25.

Pant, I. and Baroudi, B. (2008). Project management education: the human skills imperative. International Journal of Project Management, 26(2), 124-128. doi: 10.1016/j.ijproman.2007.05.010

Phillips, J. and Stone, R. (2002). How to measure training results: a practical guide to tracking the six key indicators. New York: McGraw-Hill, 284.

Phillips, P. and Phillips, J. (2007). The value of learning: how organizations capture value and ROI and translate them into support, improvement, and funds. San Francisco: Pfeiffer, xxxi, 425 p.

Project Management Institute (2008). A guide to the project management body of knowledge (PMBOK ${ }^{\circledR}$ Guide), 4th Edition. Newtown Square, Pennsylvania: PMI, Inc., 467.

Rapport, M. (2009). Project management software helps WSECU keep 'AtTask'. Credit Union Times, Summit Business Media. 20, 24.

Raymond, L. and Bergeron, F. (2008). Project management information systems: An empirical study of their impact on project managers and project success. International Journal of Project Management, 26(2), 213-220. doi: 10.1016/j.ijproman.2007.06.002

Russell, T. (2001). The no significant difference phenomenon: A comparative research annotated bibliography on technology for distance education: IDECC, North Carolina State University, 119.

Salas, E. and Cannon-Bowers, J. A. (2001). The science of training: a decade of progress. Annual Review of Psychology, 52(1), 471-499. doi: 10.1146/annurev.psych.52.1.471

Sitzmann, T., Kraiger, K., Stewart, D., and Wisher, R. (2006). The comparative effectiveness of web-based and classroom instruction: A meta-analysis. Personnel Psychology, 59(3), 623-664. doi: 10.1111/j.17446570.2006.00049.x

Symons, C. (2009). The ROI of project portfolio management tools. Cambridge, Massachusetts: Forrester Research, 1-13.

Thomas, J. and Mullaly, M. (2007). Understanding the value of project management: first steps on an international investigation in search of value. Project Management Journal, 38(3), 74-89. doi:10.1002/pmj. 20007

Thomas, J. and Mullaly, M. (2008). Researching the value of project management. Newtown Square, Pennsylvania: Project Management Institute, 458.

Wei, L., Songzheng, Z., Yiran, S. and Ming, Y. (2008). An approach to project management information system requirements analysis. 2008 Int. Conf. on Intelligent Computation Technology and Automation (ICICTA), Hunan, China, 957-961.

Wright, B. D. (1977). Solving measurement problems with the Rasch model. Journal of Educational Measurement, 14(2), 97-116. doi:10.1111/j.17453984.1977.tb00031.x

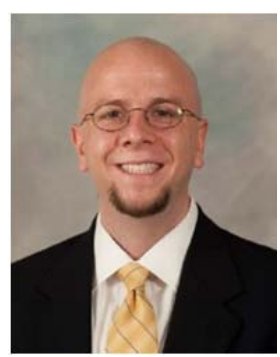

Dr. Andrew McCarty is a Senior Project Manager and Specialist within the School of Public Health at the University of Maryland, College Park. Dr. McCarty's research focuses on project management, technology systems, data analytics, quantitative methods, learning, organizational change projects, and achieving strategic objectives. Dr. McCarty holds Ph.D. and M.Eng. degrees with concentrations in Project Management from the Department of Civil and Environmental Engineering within the University of Maryland, College Park. Dr. McCarty also holds a bachelor's degree in physics, is PMP certified by the 
Project Management Institute (PMI), and is active in many professional and academic organizations.

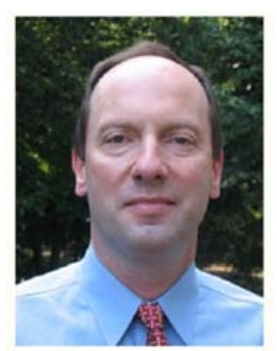

Dr. Miroslaw J. Skibniewski is the A. James Clark Chair Professor of Construction Project Management. Prior to his appointment at the University of Maryland he served for 20 years as a faculty member and administrator at Purdue University in West Lafayette, Indiana. He received his M.Eng. degree from Warsaw University of Technology, and his M.S. and Ph.D. degrees from Carnegie-Mellon University. As a researcher and educator, Professor Skibniewski currently specializes in information technology applications to engineering project management for construction. 